\title{
Twenty-first century laparoscopic hysterectomy: should we not leave the vaginal step out?
}

\author{
A. R. H. Twijnstra • N. A. Kianmanesh Rad • \\ M. J. G. H. Smeets • J. F. Admiraal • F. W. Jansen
}

Received: 17 October 2008 / Accepted: 4 March 2009/Published online: 21 March 2009

(C) The Author(s) 2009. This article is published with open access at Springerlink.com

\begin{abstract}
The objective of this study was to compare surgical outcomes for laparoscopically assisted vaginal hysterectomy (LAVH) with total laparoscopic hysterectomy (TLH) in three teaching hospitals in the Netherlands. This study is a multicenter cohort retrospective analysis of consecutive cases (Canadian Task Force classification II2). One hundred and four women underwent a laparoscopic hysterectomy between March 1995 and March 2005 at one of three teaching hospitals. This included 37 women who underwent LAVH and 67 who underwent TLH. Blood loss, operating time, and intraoperative complications such as bladder or ureteric injury as well as conversion to an open procedure were recorded. In the TLH group, average age was statistically significant lower, as well as the mean parity, whereas estimated uterus size was statistically significant larger, compared to the LAVH group. Main indication in both groups was dysfunctional uterine
\end{abstract}

\footnotetext{
A. R. H. Twijnstra • F. W. Jansen $(\bowtie)$

Department of Gynecology, Leiden University Medical Center,

K-6-P, room no. 76, P.O. Box 9600, 2300 RC, Leiden,

The Netherlands

e-mail: F.W.Jansen@lumc.nl

N. A. Kianmanesh Rad

Department of Gynecology, IJsselland Hospital,

Capelle a/d IJssel, The Netherlands

M. J. G. H. Smeets

Department of Gynecology, Bronovo Hospital,

The Hague, The Netherlands

J. F. Admiraal

Department Gynecology, Groene Hart Hospital,

Gouda, The Netherlands
}

bleeding. In the TLH group, mean blood loss (173 mL) was significant lower compared to the LAVH group $(457 \mathrm{~mL})$, whereas length of surgery, uterus weight, and complication rates were comparable between the two groups. The method of choice at the start of the study period was LAVH, and by the end of the study period, it had been superceded by TLH. LAVH should not be regarded as the novice's laparoscopic hysterectomy. Moreover, with regard blood loss, TLH shows advantages above LAVH. This might be due to the influence of the altered anatomy in the vaginal stage of the LAVH procedure. Therefore, when a vaginal hysterectomy is contraindicated, TLH is the procedure of choice. LAVH remains indicated in case of vaginal hysterectomy with accompanying adnexal surgery.

Keywords Comparative study · Hysterectomy [methods] · Postoperative complications $\cdot$ LAVH $\cdot$ TLH

\section{Introduction}

Hysterectomy is the most frequently performed major gynecologic surgical procedure annually throughout the world [1]. The most common indication for hysterectomy is uterine fibroids, followed by dysfunctional uterine bleeding [2]. Regarding the procedure, three different approaches can be distinguished-abdominal, vaginal, and laparoscopic. Traditionally, abdominal hysterectomy (AH) has been used for Gynecological malignancy or if the uterus is enlarged. Vaginal hysterectomy $(\mathrm{VH})$ was originally used only for prolapse, but it is now also used for dysfunctional uterine bleeding when the uterus is of fairly normal size [3]. Laparoscopic hysterectomy (LH) was introduced in 1988 and published in 1989 by Harry Reich as an alternative to 
abdominal hysterectomy. The first LH was set up as LH, as both uterine arteries were ligated laparoscopically, and most of the vagina opened laparoscopically. In 1992, already Reich described his foremost total laparoscopic hysterectomy (TLH) [4]. However, in the 1990s, most gynecologists "adopted" the alternative laparoscopic-assisted vaginal hysterectomy (LAVH), an operation in which the upper blood supply to the uterus was ligated laparoscopically followed by a vaginal hysterectomy. Laparoscopic hysterectomy in general requires other technical skills than the vaginal or abdominal method [5].

A recent meta-analysis compared the three methods stated above in detail [3]. Significantly improved outcomes already confirmed that VH should be performed in preference to $\mathrm{AH}$ whenever possible. $\mathrm{LH}$ (in general) can avoid the abdominal approach and shows benefits in lower intraoperative blood loss, smaller drop in hemoglobin level, shorter duration of hospital stay, speedier return to normal activities, fewer wound, or abdominal wall infections, fewer unspecified infections, however, at the cost of longer operating time and more urinary tract (bladder or ureter) injuries $[3,6-10]$.

When it comes to laparoscopic hysterectomy, a variety of associated operations can be distinguished. Garry et al. delineated this evolution of different LH procedures in Table 1 [11]. Whereas several prospective studies already thoroughly compared the LH in general versus conventional hysterectomy methods, unfortunately, no proper randomized controlled trial comparing LAVH versus TLH has been set up yet. Until now, only expert's opinions are available [5]. Therefore, this retrospective study aims to compare recorded data on two types of LH, i.e., LAVH and TLH, with respect to indication, operative characteristics, and adverse outcomes. The results could indicate whether a prospective study should be designed or not.

LAVH, introduced as a "prototype" of laparoscopic hysterectomy in the early 1990s of the last century, has a reputation for its easy implementation into daily practice as well as being an often overused expensive procedure [5].
The latter can be explained as skilled vaginal surgeons rarely find the addition of a laparoscope necessary. TLH, on the other hand, faces a slow implementation rate in many clinics due to required new and complex laparoscopic skills and extensive length of surgery [12]. Especially in the Netherlands, LH knows a slow implementation rate $(4 \%$ of all hysterectomies) possibly because of a tradition in vaginal hysterectomy.

Since the introduction of $\mathrm{LH}$ in the Netherlands, $\mathrm{AH}$ shows a declining trend [13]. Both $\mathrm{LH}$ and $\mathrm{VH}$ are practiced more often, the latter demonstrating a steeper implementation curve. With the slow but significant move from LAVH to TLH, this study aims to analyze these two procedures in order to highlight possible differences.

\section{Materials and methods}

Three teaching hospitals (of which one is a university hospital) in the west urban area of the Netherlands, which introduced LH in the same era, participated in this retrospective study. Each teaching hospital practiced identical techniques (regarding LAVH, TLH, and supracervical laparoscopic subtotal hysterectomy (SLH)). From the beginning, Harmonic Scalpel hook and bipolar forceps were used for ligation. Except for closure and suspension of the vaginal cuff, no sutures were applied. In LAVH, the vaginal cuff was closed vaginally with interrupted sutures. In TLH, the vaginal cuff was closed laparoscopically with interrupted figures-of-eight, herewith suspending the sacrouterine ligaments. Participating gynecologists were thoroughly trained vaginal surgeons with special interests in advanced laparoscopic gynecological surgery.

One hundred and four consecutive cases of women who underwent a laparoscopic hysterectomy between March 1995 and March 2005 were analyzed. This included 37 LAVHs and 67 TLHs. Three laparoscopic hysterectomies were converted intraoperatively. SLHs were excluded in order to compare the remaining two groups. As a frame of

Table 1 LH classification [11]

Laparoscopic associated hysterectomy classification

Diagnostic laparoscopy with vaginal hysterectomy
Laparoscopic-assisted vaginal hysterectomy
Laparoscopic hysterectomy
Total laparoscopic hysterectomy
Laparoscopic supracervical hysterectomy including classical interstitial Semm hysterectomy
Vaginal hysterectomy with laparoscopic vault suspension or laparoscopic pelvic reconstruction
Laparoscopic hysterectomy with lymphadenectomy
Laparoscopic hysterectomy with lymphadenectomy and omentectomy
Laparoscopic radical hysterectomy with lymphadenectomy


reference, the majority $(90 \%)$ of hysterectomies performed during this study period were either vaginal or abdominal (equally distributed).

The case history notes were manually reviewed, and epidemiological data were extracted including age, parity, estimated uterus size, and main indication. Blood loss was determined by the surgeon and recorded in the operative notes. Blood loss was invariably estimated by subtracting the applied irrigation fluid from the postoperative fluid level in the suction bottle. Possible vaginal blood loss was estimated and added to the total blood loss. The time taken to complete the procedure (skin-to-skin) was recorded from the anesthetic chart. Uterus weight was determined postoperatively. Length of stay was measured by available hospital files. Hospital stay was calculated taking day 1 as the first day following hysterectomy. Complication rates were extracted from medical charts and the weekly post surgery conferences, in which eventual adverse outcomes were discussed. Major complications (i.e., adverse outcomes demanding further treatment) were defined as blood loss exceeding $1,000 \mathrm{~mL}$, a blood transfusion due to a postoperative clinical relevant drop in Hemoglobin or bladder/ureteric injury. Minor complications (i.e., adverse outcomes recovering in absence of further treatment) were defined as occurrence of postoperative vault abscess or hematoma, urinary tract infection, or fever. Analysis was performed using SPSS 16.0 statistical software (Chicago, IL, USA). Differences between groups were assessed with the Chisquare test for proportions in independent samples and $t$ tests for continuous variables, nonparametric Kolmogorov-Smirnov $Z$ tests and Wilcoxon rank sum tests were used to asses normal distribution and to assess differences if parameters lacked a normal distribution (e.g., blood loss), $95 \%$ confidence intervals $(95 \% \mathrm{CI})$ were calculated, $P<0.05$ were considered statistically significant.

\section{Results}

Women in the TLH group were statistically significant younger and had a lower parity compared to the women in the LAVH group (Table 2). In the latter group the main indication for hysterectomy was significantly more frequently the existence of a (pre) malignancy, whereas in the TLH group statistically significant more frequently the main indication was dysfunctional uterine bleeding.

Table 3 details the intraoperative and postoperative parameters in the LAVH and TLH groups. Mean estimated blood loss ( \pm SD) was $456.8 \mathrm{~mL}( \pm 893.7)$ and $173.1 \mathrm{~mL}$ $( \pm 188.2)$ in LAVH and TLH groups, respectively $(P<0.05)$. In the LAVH and TLH groups, mean length of surgery was $144.3 \mathrm{~min}( \pm 40.0$; range $90-255)$ and $150.7 \mathrm{~min}( \pm 47.7$; range 60-320), respectively. Mean uterus weight was $165.3 \mathrm{~g}( \pm 120.7)$ and $207.2 \mathrm{~g}( \pm 120.7)$, respectively. These differences are not statistically significant. Length of patient stay was 6.1 days $( \pm 2.1)$ and 4.3 days $( \pm 2.0)$, respectively $(P<0.05)$. As a frame of reference, in The Netherlands, as in many neighboring countries, "overnight" stay for a $\mathrm{L}$ (AV)H is highly unusual.

One woman in the LAVH group as well as one woman in the TLH group sustained a blood loss in excess of $1,000 \mathrm{~mL}$. Three women in the LAVH group and two women in the TLH group needed a blood transfusion due to a postoperative clinical relevant drop in hemoglobin. After excluding the patients with blood loss in excess of $1,000 \mathrm{~mL}$, analysis still yielded a significantly higher mean estimated blood loss in the LAVH group $(312.5 \pm 171.7 \mathrm{~mL})$ versus the TLH group $(157.6 \pm 139.6 \mathrm{~mL} ; P<0.05)$.

Linear regression revealed no statistically significant association between uterine weight and estimated blood loss or length of surgery in both groups.

Major and minor complications are detailed in Table 4. Almost $22 \%$ of LAVH cases were associated with a

Table 2 Patient characteristics: in the TLH group a significantly younger age, lower parity and higher estimated uterus size was observed

\begin{tabular}{|c|c|c|c|c|c|c|c|c|c|c|c|}
\hline & \multicolumn{5}{|c|}{ LAVH $(n=37)$} & \multicolumn{5}{|c|}{ TLH $(n=67)$} & \multirow{2}{*}{$\begin{array}{l}P \\
\text { value }\end{array}$} \\
\hline & Mean & $\pm \mathrm{SD}$ & (range) & $N$ & $\begin{array}{l}\text { Percentage } \\
(\%)\end{array}$ & Mean & $\pm \mathrm{SD}$ & (range) & $N$ & $\begin{array}{l}\text { Percentage } \\
(\%)\end{array}$ & \\
\hline Age (years) & 50.5 & \pm 10.3 & $(30.2-77.8)$ & & & 45.7 & \pm 5.8 & $(32.6-64.8)$ & & & $<0.05$ \\
\hline Parity & 2.2 & \pm 1.1 & $(0-5)$ & & & 1.4 & \pm 1.3 & $(0-5)$ & & & $<0.05$ \\
\hline $\begin{array}{l}\text { Estimated uterus size } \\
\text { (weeks) } \\
\text { Main indication }\end{array}$ & 9.5 & \pm 3.5 & $(6-16)$ & & & 11.7 & \pm 3.6 & $(6-16)$ & & & $<0.05$ \\
\hline $\begin{array}{l}\text { Dysfunctional uterine } \\
\text { bleeding }\end{array}$ & & & & 19 & 51.4 & & & & 55 & 82.1 & $<0.05$ \\
\hline $\begin{array}{l}\text { - (pre)malignancy/ } \\
\text { prophylaxis }\end{array}$ & & & & 14 & 37.8 & & & & 7 & 10.4 & $<0.05$ \\
\hline - Pelvic discomfort & & & & 2 & 5.4 & & & & 5 & 7.5 & N.S. \\
\hline - Prolapse & & & & 2 & 5.4 & & & & 0 & 0 & N.S. \\
\hline
\end{tabular}


Table 3 Intraoperative and postoperative parameters

\begin{tabular}{|c|c|c|c|c|c|c|c|}
\hline & \multicolumn{3}{|c|}{ LAVH $(n=37)$} & \multicolumn{3}{|c|}{ TLH $(n=67)$} & \multirow[t]{2}{*}{$P$ value } \\
\hline & Mean & $\pm \mathrm{SD}$ & (range) & Mean & $\pm \mathrm{SD}$ & (range) & \\
\hline Blood loss (mL) & 456.8 & \pm 893.7 & $(100-5,650)$ & 173.1 & \pm 188.2 & $(0-1,200)$ & $<0.05$ \\
\hline Length of surgery (min) & 144.3 & \pm 40.0 & $(90-255)$ & 150.7 & \pm 47.7 & $(60-320)$ & N.S. \\
\hline Uterus weight (g) & 165.3 & \pm 120.7 & $(40-560)$ & 207.2 & \pm 120.7 & $(50-620)$ & N.S. \\
\hline Length of patient stay (days) & 6.1 & \pm 2.1 & $(3-12)$ & 4.4 & \pm 2.1 & $(2-12)$ & $<0.05$ \\
\hline
\end{tabular}

The LAVH group shows a significantly higher blood loss, with comparable length of surgery and uterus weight

complication compared to $28 \%$ of TLH cases $(P=0.45)$. Regarding major complications exclusively, $10.8 \%$ of LAVH cases were complicated compared to $7.5 \%$ of TLH cases. Regarding minor complications exclusively, $10.8 \%$ of LAVH cases were complicated versus $20.1 \%$ of TLH cases. Both morbidity subgroups yielded no statistically significant differences.

Three laparoscopic hysterectomies were converted intraoperatively due to a complication (twice due to insufficient hemostasis, once due to a profuse bleeding of the uterine artery which failed to be sutured laparoscopically). Without exception, the conversions took place in the TLH group.

\section{Discussion}

In this study, TLH shows considerable advantages over LAVH with respect to blood loss, with comparable length of surgery and complication rates.

Several possible explanations for these differences should be stated. First of all, it must be considered that participating surgeons during this study period were still in their learning curve. Furthermore, during the transition period from LAVH to TLH (range period of LAVH expertise, 28-106 months) laparoscopic skills of the surgeons were already more refined, which may contribute to more favorable outcomes in the TLH group. However, the initial experience with TLH was achieved with a major adjustment to technique and, thus, represents a learning curve of its own, as has been verified in similar studies [14, 15]. In contrast with the general opinion that TLH is characterized as a procedure rather challenging to acquire, several studies show a reasonable learning curve not seldom similar to conventional open methods [16-19]. Concerning the evolvement of instrumentation, we would like to notify that every LH in this study was performed with the use of ultrasonic and bipolar energy. In contrast with other publications, no suture ligation (except for vaginal cuff closure) was applied [20].

Moreover, it is recognized that the groups vary in terms of patient characteristics and main indication. Women who underwent LAVH were prone to be older and above all,

Table 4 Major and minor complications: complication rates are comparable between the two groups

\begin{tabular}{|c|c|c|c|c|c|}
\hline & \multicolumn{2}{|l|}{ LAVH $(n=37)$} & \multicolumn{2}{|l|}{ TLH $(n=67)$} & \multirow[t]{2}{*}{$P$ value } \\
\hline & Parameters $(N)$ & Percentage $(\%)$ & Parameters $(N)$ & Percentage $(\%)$ & \\
\hline \multicolumn{6}{|l|}{ Major complications } \\
\hline Blood loss $>1,000 \mathrm{~mL}$ & 1 & 2.7 & 1 & 1.5 & N.S. \\
\hline Blood transfusion $^{\mathrm{a}}$ & 3 & 8.1 & 2 & 3.0 & N.S. \\
\hline Ureteric injury & 0 & 0 & 2 & 3.0 & N.S. \\
\hline \multicolumn{6}{|l|}{ Minor complications } \\
\hline Vault abcess/haematoma & 1 & 2.7 & 3 & 4.5 & N.S. \\
\hline Urinary tract infection & 1 & 2.7 & 4 & 6.0 & N.S. \\
\hline Fever & 2 & 5.4 & 4 & 6.0 & N.S. \\
\hline Technical failure ${ }^{\mathrm{b}}$ & 0 & 0 & 3 & 4.5 & N.S. \\
\hline Total & 8 & 21.6 & 19 & 28.4 & N.S. \\
\hline
\end{tabular}

${ }^{\text {a With blood loss }<1,000 \mathrm{~mL}}$

${ }^{\mathrm{b}}$ Unable to ligate the uterine laparoscopically (1), needle lost and found (2) 
more multiparous at the time of the intervention compared to women who underwent TLH. Taking into account the extension of indications in the field of laparoscopic hysterectomy during this study period, in which time for example fewer enlarged uteri were removed conventionally, meanwhile a decline in age (accompanied with an on average bigger uterus) is shown. The latter might explain the found differences.

In addition, the most remarkable finding in this study is the striking higher mean blood loss in the LAVH group, which is confirmed by other studies [14, 15]. As stated above, position of the surgeon in her/his learning curve and ongoing technical innovations do partially explain this difference. However, in addition to this, we would like to mention the possible influence of the altered anatomy of the corpus uteri and surroundings in the vaginal stage of the LAVH procedure, inflicting the surgeon's familiar sight of anatomical landmarks. On the other hand, when it comes to uteri without descensus, some surgeons claim to create descensus by applying LAVH. However, their line of thought that disconnecting the pedicles of the round ligament as well as the cardinal ligament will facilitate descensus laparoscopically does not hold. In our opinion, descensus is directly related to the firmness of the uterosacral ligaments [21-23]. In the classical LAVH, these ligaments are clamped vaginally. Therefore, being developed as an alternative to abdominal hysterectomy the laparovaginal approach should be regarded as rather illogical.

The arguments stated above contribute to our opinion that LAVH nowadays knows fewer indications compared to the era of its introduction. In fact, in presence of sufficient descensus and an introitus wide enough to have the operation field exposed, both needed to perform LAVH, a vaginal hysterectomy is proved to be preferable regardless of estimated uterus size [3, 20, 24]. The LAVH (levels 1-3 in the Garry classification, Table 1) remains solely indicated in case of vaginal hysterectomy, with expected adhesions or endometriosis hindering vaginal surgery or planned accompanying adnexal surgery.

At this point in history, at which every comparison study concerning the putative advantages of one form of surgery over another preferably is designed as a randomized clinical trial, we strongly recommend to keep in mind the outcomes of retrospective studies like this [10, 25, 26].

Although we confirm the advantages of a prospective comparison between these two types of surgery, we must be taken aware of distinct differences as observed in this study. Of course, the improved global experience with $\mathrm{LH}$ in general does add to better outcomes in the TLH group in comparison with the "historical" LAVH group. However, as TLH now proves to be a safe procedure that can be achieved with low blood loss, LAVH still happens to know a higher mean blood loss due to the earlier mentioned altered anatomy [14, 15].

Concerning observed complications, even with improved techniques, this study shows a ureteric injury rate of $3 \%$ in the TLH group, which is comparable with other complication studies [7, 8]. However, as is confirmed by a recent study, we expect this rate to decline to a rate comparable with the abdominal approach after completing the learning curve for this procedure [27]. Both ureter lesions during this study were recognized postoperatively and before discharge. Both patients required repair by laparotomy.

In conclusion, the results from our study show that LAVH should not be regarded as the novice's laparoscopic hysterectomy. The LAVH should be considered as an specific surgical approach with its own distinctive indication. Vaginal hysterectomy should remain "no. 1" in the domain the gynecological surgeon. VH should, therefore, remain incorporated in the arsenal of the gynecologist-intraining, apart from training in laparoscopy. Expert vaginal surgeons need to train laparoscopic skills in a safe environment (skills lab, assisting salpingo ophorectomies, etc.) before one can start doing the incidental LAVH. Surgeons who are well trained in $\mathrm{VH}$ and consider acquiring skills in LH should keep in mind the flow chart as depicted in Fig. 1. If gynaecologists receive appropriate surgical training in laparoscopic techniques, TLH is a recommended option in case of a vaginally inapproachable uterus. In our opinion laparoscopic hysterectomy should not assist vaginal surgery when no additional (adnexal) pathology is present.

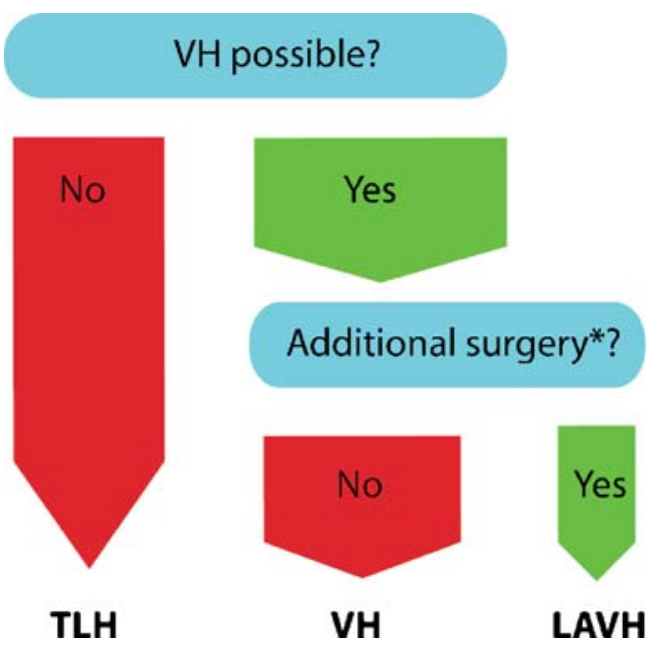

Fig. 1 Flowchart indicating method of choice in laparovaginal hysterectomy. *additional surgery $=$ expected adhesions, endometriosis or adnexal pathology. ( $V H$ vaginal hysterectomy; TLH total laparoscopic hysterectomy; $L A V H$ laparoscopic assisted vaginal hysterectomy) 
Open Access This article is distributed under the terms of the Creative Commons Attribution Noncommercial License which permits any noncommercial use, distribution, and reproduction in any medium, provided the original author(s) and source are credited.

\section{References}

1. Garry R (2005) Health economics of hysterectomy. Best Pract Res Clin Obstet Gynaecol 19:451-465

2. Garry R (2005) The future of hysterectomy. BJOG 112:133-139

3. Johnson N, Barlow D, Lethaby A, Tavender E, Curr E, Garry R. Surgical approach to hysterectomy for benign gynaecological disease. Cochrane Database Syst Rev. 2006;CD003677.

4. Reich H (1992) Laparoscopic hysterectomy. Surg Laparosc Endosc 2:85-88

5. Reich H (2007) Total laparoscopic hysterectomy: indications, techniques and outcomes. Curr Opin Obstet Gynecol 19:337-344

6. Garry R, Fountain J, Brown J et al (2004) EVALUATE hysterectomy trial: a multicentre randomised trial comparing abdominal, vaginal and laparoscopic methods of hysterectomy. Health Technol Assess 8:1-154

7. Harkki P, Kurki T, Sjoberg J, Tiitinen A (2001) Safety aspects of laparoscopic hysterectomy. Acta Obstet Gynecol Scand 80:383-391

8. Makinen J, Johansson J, Tomas C et al (2001) Morbidity of 10110 hysterectomies by type of approach. Hum Reprod 16:1473-1478

9. Bojahr B, Raatz D, Schonleber G, Abri C, Ohlinger R (2006) Perioperative complication rate in 1706 patients after a standardized laparoscopic supracervical hysterectomy technique. J Minim Invasive Gynecol 13:183-189

10. Sarmini OR, Lefholz K, Froeschke HP (2005) A comparison of laparoscopic supracervical hysterectomy and total abdominal hysterectomy outcomes. J Minim Invasive Gynecol 12:121-124

11. Garry R, Reich H, Liu CY (1994) Laparoscopic hysterectomy definitions and indications. Gynaecol Endosc 3:1-3

12. Kolkman W, Trimbos-Kemper TC, Jansen FW (2007) Operative laparoscopy in The Netherlands: diffusion and acceptance. Eur J Obstet Gynecol Reprod Biol 130:245-248

13. Brolmann HA, Vervest HA, Heineman MJ (2001) Declining trend in major gynaecological surgery in The Netherlands during 19911998. Is there an impact on surgical skills and innovative ability? BJOG 108:743-748

14. Cook JR, O'Shea RT, Seman EI (2004) Laparovaginal hysterectomy: a decade of evolution. Aust N Z J Obstet Gynaecol 44:111-116
15. Long CY, Fang JH, Chen WC, Su JH, Hsu SC (2002) Comparison of total laparoscopic hysterectomy and laparoscopically assisted vaginal hysterectomy. Gynecol Obstet Invest 53:214-219

16. Wattiez A, Soriano D, Cohen SB et al (2002) The learning curve of total laparoscopic hysterectomy: comparative analysis of 1647 cases. J Am Assoc Gynecol Laparosc 9:339-345

17. Leminen A (2000) Comparison between personal learning curves for abdominal and laparoscopic hysterectomy. Acta Obstet Gynecol Scand 79:1100-1104

18. Malzoni M, Perniola G, Perniola F, Imperato F (2004) Optimizing the total laparoscopic hysterectomy procedure for benign uterine pathology. J Am Assoc Gynecol Laparosc 11:211-218

19. Kolkman W, Engels LE, Smeets MJ, Jansen FW (2007) Teach the teachers: an observational study on mentor traineeship in gynecological laparoscopic surgery. Gynecol Obstet Invest 64:1-7

20. Garry R, Fountain J, Mason S et al (2004) The eVALuate study: two parallel randomised trials, one comparing laparoscopic with abdominal hysterectomy, the other comparing laparoscopic with vaginal hysterectomy. BMJ 328:129

21. Possover M, Krause N, Kuhne-Heid R, Schneider A (1998) Laparoscopic assistance for extended radicality of radical vaginal hysterectomy: description of a technique. Gynecol Oncol 70:9499

22. Buller JL, Thompson JR, Cundiff GW, Krueger SL, Schon Ybarra MA, Bent AE (2001) Uterosacral ligament: description of anatomic relationships to optimize surgical safety. Obstet Gynecol 97:873-879

23. Schwartz M, Abbott KR, Glazerman L et al (2007) Positive symptom improvement with laparoscopic uterosacral ligament repair for uterine or vaginal vault prolapse: interim results from an active multicenter trial. J Minim Invasive Gynecol 14:570-576

24. Darai E, Soriano D, Kimata P, Laplace C, Lecuru F (2001) Vaginal hysterectomy for enlarged uteri, with or without laparoscopic assistance: randomized study. Obstet Gynecol 97:712-716

25. Taylor SM, Romero AA, Kammerer-Doak DN, Qualls C, Rogers RG (2003) Abdominal hysterectomy for the enlarged myomatous uterus compared with vaginal hysterectomy with morcellation. Am J Obstet Gynecol 189:1579-1582

26. Lenihan JP Jr, Kovanda C, Cammarano C (2004) Comparison of laparoscopic-assisted vaginal hysterectomy with traditional hysterectomy for cost-effectiveness to employers. Am J Obstet Gynecol 190:1714-1720

27. Brummer TH, Seppala TT, Harkki PS. National learning curve for laparoscopic hysterectomy and trends in hysterectomy in Finland 2000-2005. Hum Reprod. 2008 